\title{
Synthesis of Titanium Phosphates with Additives and Their Powder Properties for Cosmetics
}

\author{
Hiroaki Onoda*, Taisuke Yamaguchi \\ Department of Informatics and Environmental Sciences, Kyoto Prefectural University, Kyoto, Japan. \\ Email: *onoda@kpu.ac.jp \\ Received November $5^{\text {th }}, 2011$; revised December $17^{\text {th }}, 2011$; accepted December $30^{\text {th }}, 2011$
}

\begin{abstract}
As a white pigment, titanium oxide is used for cosmetic application. This oxide is well known to have the photo catalytic activity. Therefore a certain degree of sebum is decomposed by the ultraviolet radiation in sunlight. In this work, titanium phosphates were prepared with additives (urea, sodium lactate, and glycerin) as a novel white pigment. Their chemical composition, powder properties, photo catalytic activity, moisture retention, and smoothness were studied. These white pigments had little photo catalytic activity. The addition of sodium lactate and glycerin improved the moisture retention of titanium phosphates. The slipping resistance of samples became small by the addition of sodium lactate and glycerin. The roughness of samples became small by heating.
\end{abstract}

Keywords: Titanium Phosphates Additives; Photo Catalytic Activity; Moisture Retention; Smoothness

\section{Introduction}

As a white pigment, titanium dioxide is used for cosmetic application [1]. This oxide is well known to have the photo catalytic activity. Therefore, a certain degree of sebum is decomposed by the ultraviolet radiation in sunlight. To repress this effect, some kinds of process are investigated and used. For example, as one of these techniques, the composite particles with silicon oxide are used [2]. However, these particles are hard materials for human face. The mild materials for human face are required as a white pigment. In addition, there was a report that microfine titanium dioxide would be adsorbed through the skin [3]. The novel white pigment that is not adsorbed is required.

Phosphates have been used for ceramic materials, catalysts, adsorbent, fluorescent materials, dielectric substances, biomaterials, for metal surface treatment, as fertilizer, detergents, food additives, in fuel cells, pigments, and other items [4-8]. It is well known that phosphate materials have high affinity for a living body. Therefore, as a novel white pigment, phosphates have a possibility for the cosmetics.

For the cosmetics, the moisture retention of materials is important to prevent the dry skin. Generally, urea is added to improve this moisture retention [9]. In previous work [10], the addition of urea had influence on the particle properties of inorganic phosphate materials. Spheri-

${ }^{*}$ Corresponding author. cal particles and large specific surface area were obtained in the preparation of lanthanum phosphate by the addition of urea. The particle shape of the pigment has influence on the smoothness of materials [11-13]. The smoothness of pigment is also important for the cosmetic applications. The white pigment with high smoothness spreads well on the skin. Further, sodium lactate and glycerin are easy to keep water in materials. Therefore, these compounds are used for cosmetics. Sodium lactate is considered to have antioxidant properties [14].

In this work, titanium phosphates were prepared from titanium chloride and phosphoric acid solution, with the addition of urea, sodium lactate, and glycerin. Their chemical composition, powder properties, photo catalytic activity, moisture retention, and smoothness of the obtained precipitates and their thermal products were studied for the cosmetic application.

\section{Experimental Procedure}

$0.1 \mathrm{~mol} / \mathrm{l}$ of titanium chloride solution was mixed with $0.1 \mathrm{~mol} / \mathrm{l}$ of phosphoric acid solution in a molar ratio of $\mathrm{Ti} / \mathrm{P}=1 / 1$. Urea, sodium lactate, and glycerin were added in the phosphoric acid solution to $0.5 \mathrm{~mol} / \mathrm{l}$ before the mixing [10]. The mixing conditions were shown in Table 1. Then, the precipitates were filtered off, washed with water, and dried. These samples were settled as "sample A-H" in this paper.

A part of the precipitates was dissolved in hydrochloric acid solution. The ratios of phosphorus and titanium in 
Table 1. Ti/P ratio in precipitates and specific surface area (SSA) of thermal products at $200^{\circ} \mathrm{C}$.

\begin{tabular}{cccccc}
\hline Sample & Urea & Sodium lactate & Glycerin & Ti/P & SSA \\
\hline & $/ \mathrm{mol} \cdot \mathrm{l}^{-1}$ & $/ \mathrm{mol} \cdot \mathrm{l}^{-1}$ & $/ \mathrm{mol}^{-1} \mathrm{l}^{-1}$ & & $/ \mathrm{m}^{2} \cdot \mathrm{g}^{-1}$ \\
A & 0 & 0 & 0 & 1.19 & 11.6 \\
B & 0.5 & 0 & 0 & 1.25 & 0.315 \\
C & 0 & 0.5 & 0 & 1.63 & 181 \\
D & 0 & 0 & 0.5 & 1.61 & 15.3 \\
E & 0.5 & 0 & 0.5 & 1.63 & 17.1 \\
F & 0.5 & 0.5 & 0 & 1.43 & 154 \\
G & 0 & 0.5 & 0.5 & 1.50 & 162 \\
H & 0.5 & 0.5 & 0.5 & 1.54 & 150 \\
\hline
\end{tabular}

the precipitates were also calculated from ICP results of these solutions, using SPS1500VR, Seiko Instruments Inc. The chemical composition of these materials was analyzed by XRD. XRD patterns were recorded on a Rigaku Denki RINT 1200M X-Ray diffractometer using monochromated $\mathrm{CuK} \alpha$ radiation. TG and DTA curves were measured with a Shimadzu DTG-60H at a heating rate of $10 \mathrm{~K} \cdot$ minute $^{-1}$ in air. Samples were heated at $100^{\circ} \mathrm{C}, 200^{\circ} \mathrm{C}, 400^{\circ} \mathrm{C}, 600^{\circ} \mathrm{C}$ in air conditions. These thermal products were also analyzed by XRD.

The powder properties of precipitates and their thermal products were estimated from SEM images, particle size distributions, and specific surface area. Scanning electron microscopy (SEM) images of titanium phosphates were observed using JGM-5510LV, JEOL Ltd. The particle size distributions of these materials were measured with laser diffraction/scattering particle size distribution HO-RIBA LA-910. The specific surface area of phosphates was calculated from the amount of nitrogen gas adsorbed at the temperature of liquid nitrogen by BET method with a Belsorp mini from Bel Japan.

The cosmetic properties were estimated by the photo catalytic activity, the moisture retention, and the smoothness. The photo catalytic activity of samples was estimated with the decomposition of methylene blue by 365 $\mathrm{nm}$ radiation $[15,16]$. As the moisture retention of samples, $0.1 \mathrm{~g}$ of sample was mixed with $0.03 \mathrm{~g}$ of water, and then evaluated their weight loss under $50 \%-60 \%$ in humidity at about $20^{\circ} \mathrm{C}$. The smoothness of particles was measured on artificial leather with KES-SE objective evaluation of surface friction property, KATO Tech Co. Ltd.

\section{Results and Discussion}

\subsection{Chemical Composition of Precipitates}

Table 1 shows Ti/P ratio of precipitate calculated from ICP results. The Ti/P ratio in precipitates increased by the additives. Because all samples had higher $\mathrm{Ti} / \mathrm{P}$ ratio than the Ti/P ratio of $\mathrm{TiPO}_{4}(\mathrm{OH})$ and $\mathrm{Ti}_{3}\left(\mathrm{PO}_{4}\right)_{4}$, the hy- droxide was considered to form. The regularity by the kinds of the additives was not clear on these $\mathrm{Ti} / \mathrm{P}$ ratios. Figure 1 shows XRD patterns of samples prepared with various additives. Samples A-F were amorphous phase, on the other hand, unknown small peaks were observed in XRD patterns of samples $\mathrm{G}$ and $\mathrm{H}$. By heating at $400^{\circ} \mathrm{C}$, all samples were amorphous. Samples D, F, G, and $\mathrm{H}$ heated at $600^{\circ} \mathrm{C}$ had small peak at about 26 degree.

Figure 2 shows DTA curves of samples prepared with additives. Sample A had large endothermic peal at $100^{\circ} \mathrm{C}$ and small exothermic peak at $760^{\circ} \mathrm{C}$ on DTA curve (Figure 2(a)). These peaks were caused from the volatilization of water and the crystallization of titanium phosphate, respectively. By the addition of urea, sodium lactate, and glycerin, the exothermic peaks appeared from $240^{\circ} \mathrm{C}$ to $280^{\circ} \mathrm{C}$. Sodium lactate and glycerin produced larger exothermic peaks than urea. These peaks were caused from the burning of the additives.

Figure 3 shows TG curves of samples prepared with additives. All samples had large weight loss below $600^{\circ} \mathrm{C}$. These weight losses at $600^{\circ} \mathrm{C}$ were $50.8 \%, 41.1 \%, 41.1 \%$, $41.0 \%, 48.0 \%, 42.1 \%, 54.2 \%$, and $50.5 \%$ on TG curves of sample from A to $\mathrm{H}$, respectively. The adsorbed water decreased by the additives. Generally, the ratio of the included additives was calculated from the increase of

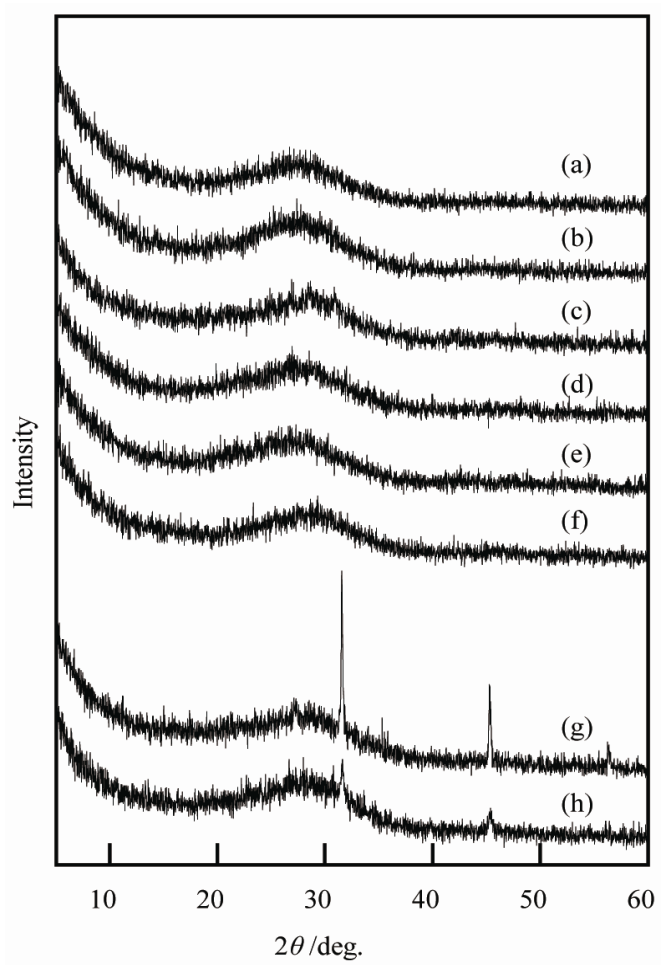

Figure 1. XRD patterns of samples prepared in various conditions, (a) Sample A; (b) Sample B; (c) Sample C; (d) Sample D; (e) Sample E; (f) Sample F; (g) Sample G; (h) Sample H. 


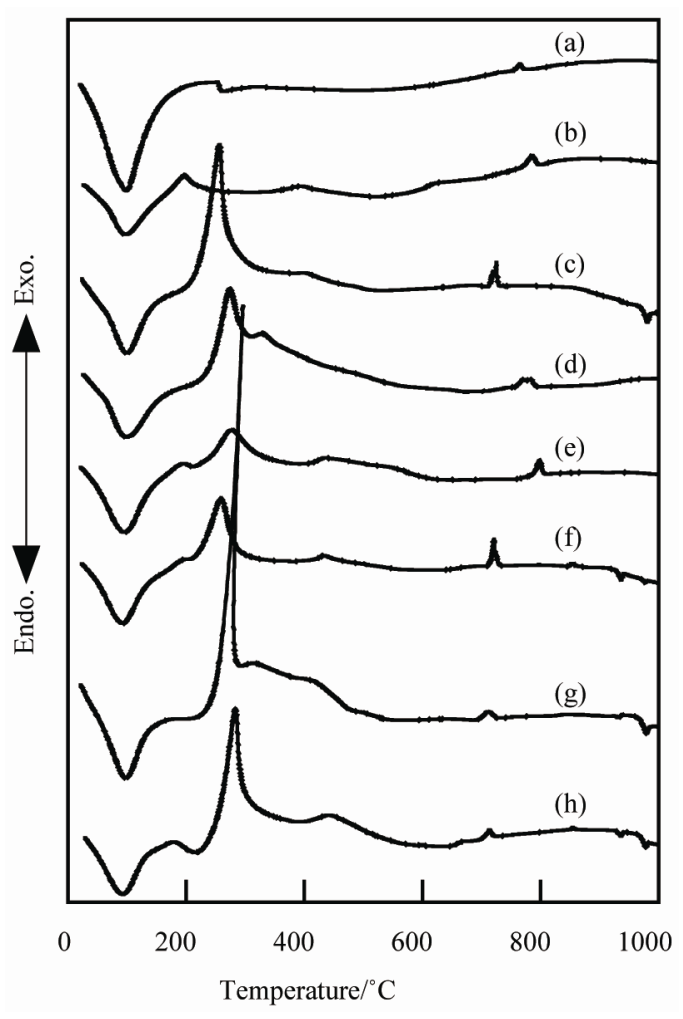

Figure 2. DTA curves of samples prepared in various conditions, (a) Sample A, (b) Sample B; (c) Sample C; (d) Sample D; (e) Sample E; (f) Sample F; (g) Sample G; (h) Sample H.

weight loss [17]. However, in this work, the ratio of the additives could not be calculated from TG curves. Because samples lost the additives by heating at high temperature, samples heated at low temperature were suitable to use as a cosmetic pigment with urea, sodium lactate, and glycerin.

\subsection{Powder Properties of Titanium Phosphates}

From the viewpoint of particle shape, spherical particles are suitable for the cosmetic applications. Figure $\mathbf{4}$ shows SEM images of samples prepared in various conditions and then heated at $100^{\circ} \mathrm{C}$. All samples had no specified shape in spite of the kind of additives. The angular particles were less observed in samples $\mathrm{G}$ and $\mathrm{H}$.

Figure 5 shows the particle size distribution of samples heated at $100^{\circ} \mathrm{C}$. The main part of particles was from 1 to $300 \mu \mathrm{m}$. The difference between samples prepared with various additives was not clear in these particle size distributions. For cosmetic application, small and homogenized particles are suitable. However, too much smaller particles had trouble to get into pores in the skin [3]. The standard size of the white pigment for cosmetics is difficult to determine, because the size of pore in the skin is determined from age, gender, climate, and so on. Samples had the distribution peaks at 3 and $30 \mu \mathrm{m}$. The

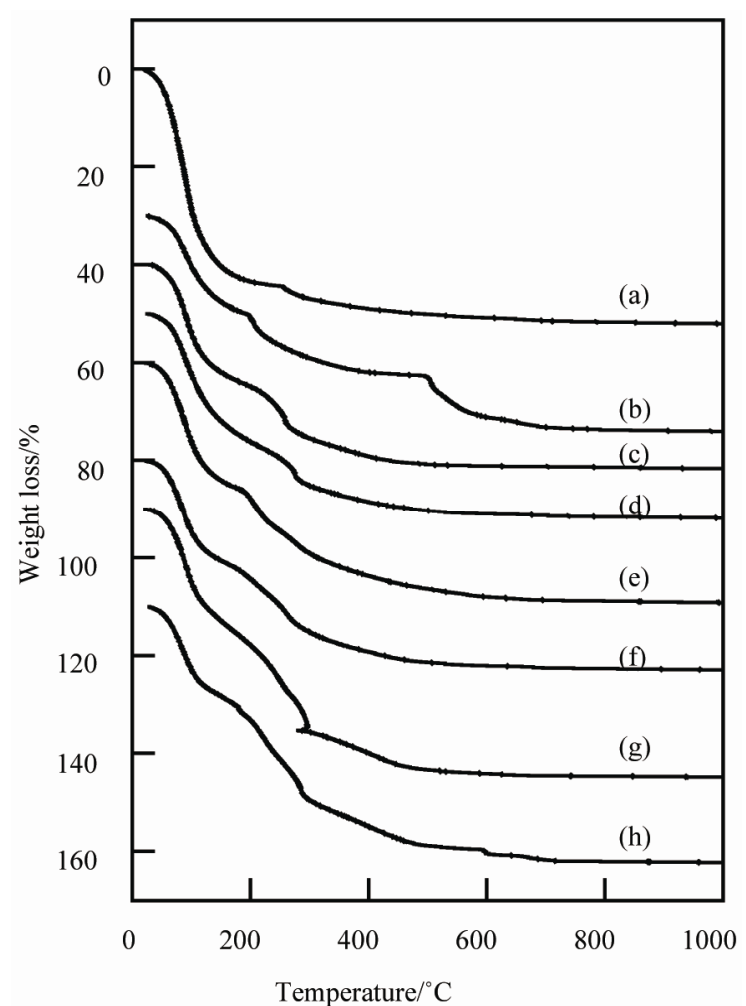

Figure 3. TG curves of samples prepared in various conditions, (a) Sample A; (b) Sample B; (c) Sample C; (d) Sample D; (e) Sample E; (f) Sample F; (g) Sample G; (h) Sample H.
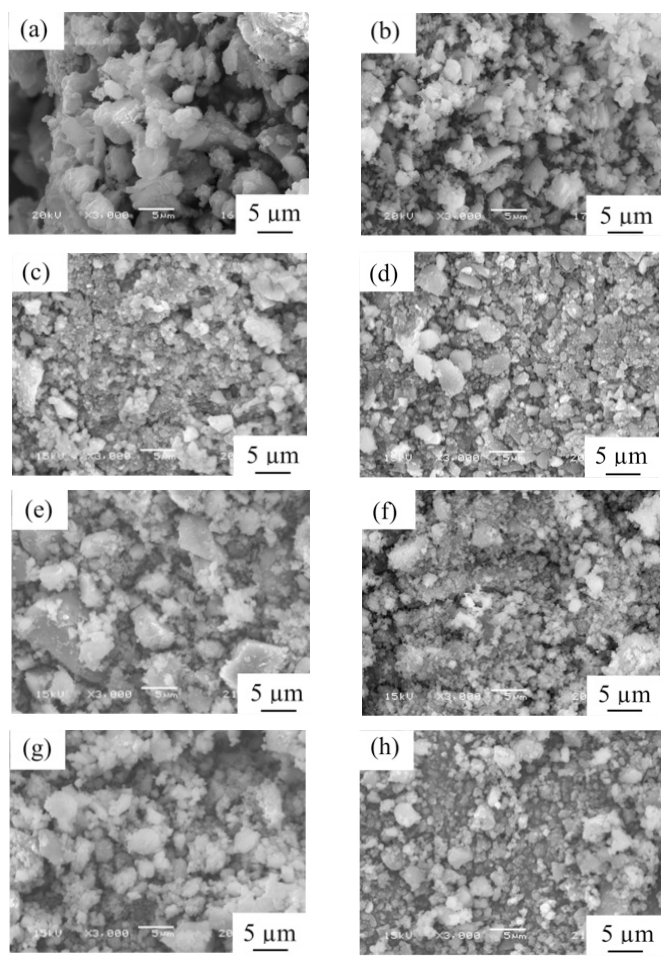

Figure 4. SEM images of samples heated at $100^{\circ} \mathrm{C}$, (a) Sample A; (b) Sample B; (c) Sample C; (d) Sample D; (e) Sample E; (f) Sample F; (g) Sample G; (h) Sample H. 


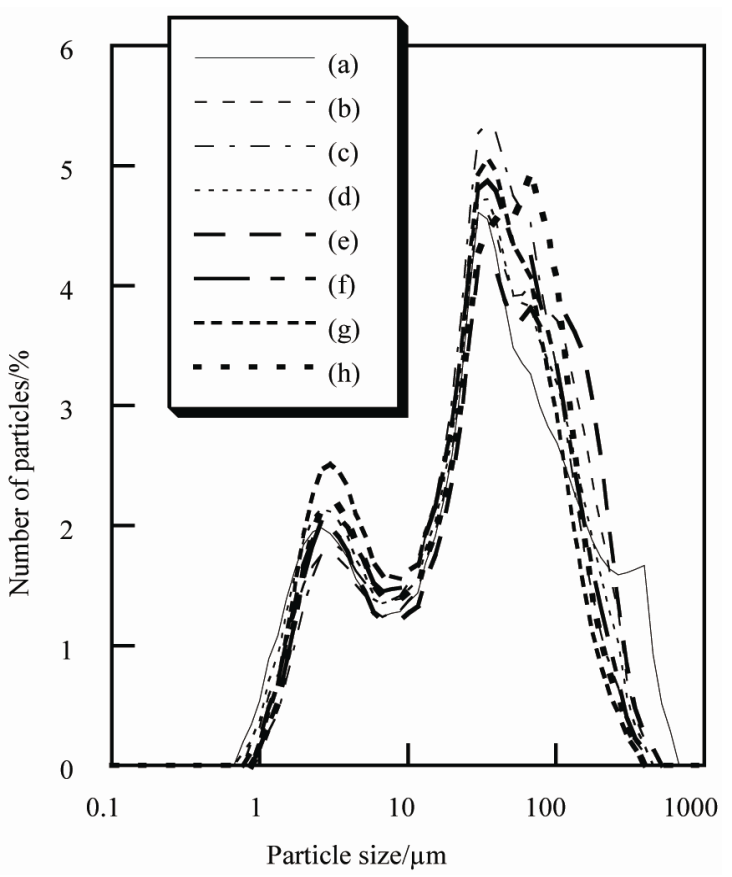

Figure 5. Particle size distribution of samples heated at $100^{\circ}$ C, (a) Sample A; (b) Sample B; (c) Sample C; (d) Sample D; (e) Sample E; (f) Sample F; (g) Sample G; (h) Sample H.

microfine particles are inappropriate because of the adsorption through the skin. Further, too much larger particles are also inappropriate because of the cracking of coating on the skin. It is important to control the particle size of pigments. Samples prepared in this work had same range of particle size with the suitable size for the cosmetics. The homogenization of particle size is felt from the further examination on preparation conditions.

\subsection{Cosmetic Properties of Titanium Phosphates}

Figure 6 shows the photo catalytic activity of samples. Because titanium dioxide is used as a white pigment in cosmetics, this compound was evaluated for the comparison with uncoated titanium phosphate [1]. The methylene blue was decomposed with titanium dioxide by UV radiation (Figure 6(d)). On the other hand, titanium phosphate had little photo catalytic activity in spite of the addition of urea (Figures 6(b)-(c)). Titanium phosphate was mild material to protect the sebum on the skin.

The moisture on the skin represses the itching and damage of the skin. The pigment for the cosmetics is important to keep the moisture on the skin [18]. Figure 7 shows the moisture retention of samples prepared in various conditions. Sample prepared without additives had larger weight loss than other samples. The additives improved the moisture retention of titanium phosphates. Especially, the improvement by sodium lactate was large. After 540 minutes, $20 \%$ of the weight loss was different

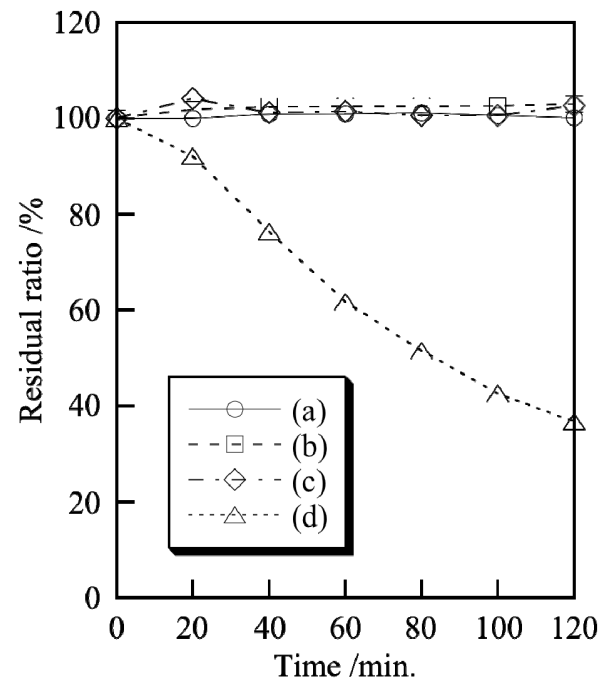

Figure 6. Photo catalytic activity of samples, (a) Blank; (b) Sample A, R. T.; (c) Sample $\mathrm{H}, \mathbf{1 0 0}^{\circ} \mathrm{C}$; (d) $\mathrm{TiO}_{2}$.

between samples A and $\mathrm{H}$. This is significant to design the pigment for the cosmetics.

As mentioned above, the pigment with high smoothness spreads well on the skin. The smoothness of the powders is also important in cosmetics [19]. Table 2 shows the smoothness of samples heated at various temperatures. The values of MIU and MMD represented the slipping resistance and roughness of powders, respectively. Sample powders spread on the article leather, and then a sensor ran on these powders. The values of MIU and MMD were calculated from the power to move a sensor and the pitching of a sensor, respectively. The heated sample $\mathrm{H}$ had smaller MIU and MMD than sample $\mathrm{H}$ without heating. Because small values of MIU and MMD are required for the cosmetics, the heated sample $\mathrm{H}$ was suitable. Table 3 shows the smoothness of samples prepared in various conditions and then heated at $100^{\circ} \mathrm{C}$. By the addition of urea, the value of MIU increased, on the other hand, other samples had smaller MIU value than sample prepared without additives. Sample E had larger MMD value than others. The smoothness of titanium phosphate was difficult to be controlled by the heating and the additives.

Table 2. Smoothness of sample $H$ heated at various temperatures.

\begin{tabular}{ccc}
\hline Temp. $/{ }^{\circ} \mathrm{C}$ & MIU & MMD $\times 10^{3}$ \\
\hline R.T. & 0.498 & 11.0 \\
100 & 0.408 & 7.8 \\
200 & 0.434 & 7.8 \\
400 & 0.478 & 7.6 \\
600 & 0.458 & 7.6 \\
\hline
\end{tabular}




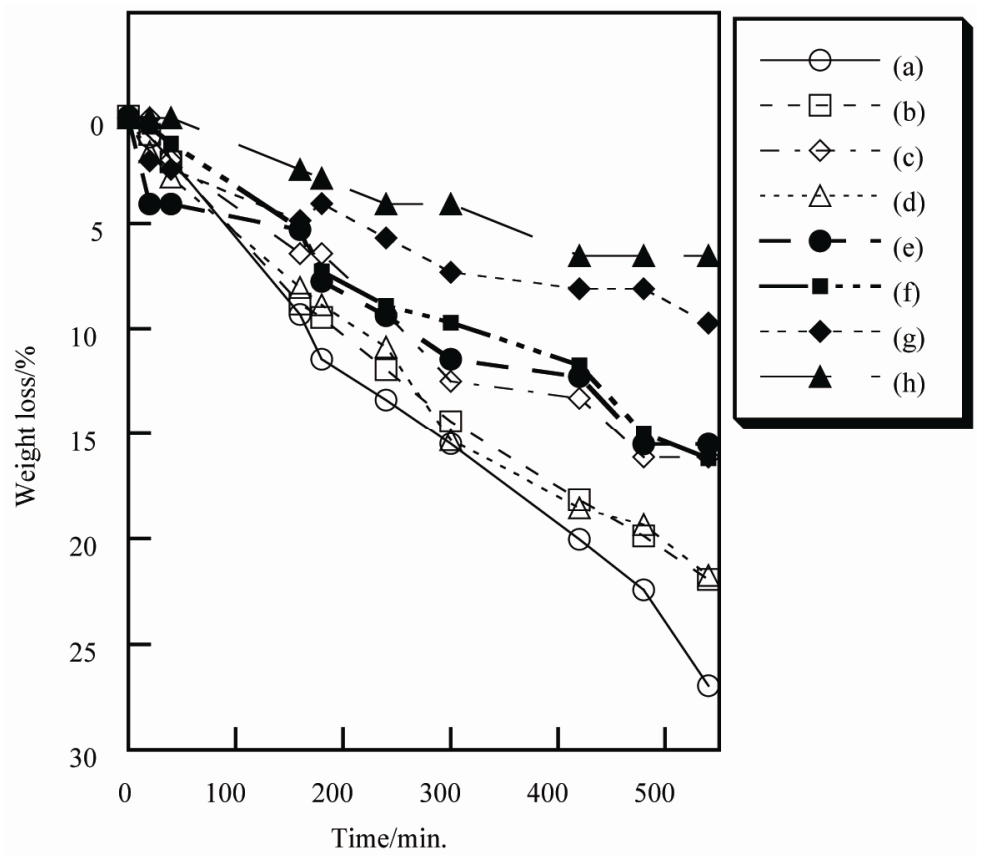

Figure 7. Moisture retention of samples heated at $100^{\circ}$ C, (a) Sample A; (b) Sample B; (c) Sample C; (d) Sample D; (e) Sample E; (f) Sample F; (g) Sample G; (h) Sample H.

Table 3. Smoothness of samples prepared in various conditions $\left(100^{\circ} \mathrm{C}\right)$.

\begin{tabular}{ccc}
\hline Sample & MIU & MMD $\times 10^{3}$ \\
\hline A & 0.582 & 3.0 \\
B & 0.628 & 3.4 \\
C & 0.460 & 7.0 \\
D & 0.478 & 8.4 \\
E & 0.478 & 10.2 \\
F & 0.442 & 8.4 \\
G & 0.412 & 7.8 \\
H & 0.408 & 7.8 \\
\hline
\end{tabular}

\section{Conclusion}

Titanium phosphates were obtained from titanium chloride and phosphoric acid with urea, sodium lactate, and glycerin. XRD patterns of the obtained materials were amorphous or had unknown weak peaks. These titanium phosphates were mild materials to protect the sebum on the skin. The addition of urea, sodium lactate, and glycerin improved the moisture retention of titanium phosphates. The slipping resistance of sample powders became small by additives.

\section{REFERENCES}

[1] U. Diebold, "The Surface Science of Titanium Dioxide," Surface Science Report, Vol. 48, No. 5-8, 2003, pp. 53229. doi:10.1016/S0167-5729(02)00100-0

[2] M. Senzuki, T. Tamura, K. Miura, Y. Ikarashi, Y. Watanabe and M. Fujii, "Study on Penetration of Titanium
Dioxide $\left(\mathrm{TiO}_{2}\right)$ Nanoparticles into Intact and Damaged Skin in Vitro," The Journal of Toxicological Sciences, Vol. 35, No. 1, 2010, pp. 107-113. doi:10.2131/jts.35.107

[3] A. O. Gamer, E. Leibold and B. Van Ravenzwaay, “The in Vitro Absorption of Microfine Zinc Oxide and Titanium Dioxide through Porcine Skin,” Toxicol in Vitro, Vol. 20, No. 3, 2006, pp. 301-307. doi:10.1016/j.tiv.2005.08.008

[4] H. Onoda, H. Nariai, A. Moriwaki, H. Maki and I. Motooka, "Formation and Catalytic Characterization of Various Rare Earth Phosphates," Journal of Materials Chemistry, Vol. 12, No. 6, 2002, pp. 1754-1760. doi:10.1039/b110121h

[5] H. Onoda, T. Ohta, J. Tamaki and K. Kojima, "Decomposition of Trifluoromethane over Nickel Pyrophosphate Catalysts Containing Metal Cation," Applied Catalysis A; General, Vol. 288, No. 1-2, 2005, pp. 98-103. doi:10.1039/b110121h

[6] D. J. Jones, G. Aptel, M. Brandhorst, M. Jacquin, J. Jimenez-Jimenez, A. Jimenez-Lopez, P. Maireles-Torres, I. Piwonski, E. Rodrigues-Castellon, J. Zajac and J. Roziere, "High Surface Area Mesoporous Titanium Phosphate: Synthesis and Surface Acidity Determination,” Journal of Materials Chemistry, Vol. 10, No. 8, 2000, pp. 19571963. doi:10.1039/b002474k

[7] H. Onoda, H. Matsui and I. Tanaka, "Improvement of Acid and Base Resistance of Nickel Phosphate Pigment by the Addition of Lanthanum Cation," Materials Science and Engineering B, Vol. 141, No. 1-2, 2007, pp. 28-33. doi:10.1016/j.mseb.2007.05.009

[8] A. Bhamik and S. Inagaki, "Mesoporous Titanium Phosphate Molecular Sieves with Ion-Exchange Capacity,” Jour- 
nal of American Chemical Society, Vol. 123, No. 4, 2001, pp. 691-696. doi:10.1021/ja002481s

[9] A. R. Baby, C. A. Haroutiounian-Filho, F. D. Sarruf, C. A. S. O. Pinto, T. M. Kaneko and M. V. R. Velasco, "Influence of Urea, Isopropanol, and Propylene Glycol on Rutin in Vitro Release from Cosmetic Semisolid Systems Estimated by Factorial Design,” Drug Development and Industrial Pharmacy, No. 35, Vol. 3, 2009, pp. 272-282. doi:10.1080/03639040802277664

[10] H. Onoda, K. Taniguchi and I. Tanaka, “Additional Effects of Urea on Preparation and Acidic Properties of Lanthanum Orthophosphate," Microporous and Mesoporous Materials, Vol. 109, No. 1-3, 2008, pp. 193-198. doi:10.1016/j.micromeso.2007.04.043

[11] D. Mohn, D. Ege, K. Feldman, O. D. Schneider, T. Imfeld, A. R. Boccaccini and W. J. Stark, "Spherical Calcium Phosphate Nanoparticle Fillers Allow Polymer Processing of Bone Fixation Devices with High Bioactivity," Polymer Engineering and Sciences, Vol. 50, No. 5, 2010, pp. 952-960. doi:10.1002/pen.21596

[12] S. Roohani-Esfahani, S. Nouri-Kohrasani, Z. Lu, R. Appleyard and H. Zreiqat, "The Influence Hydroxyapatite Nanoparticle Shape and Size on the Properties of Biphasic Calcium Phosphate Scaffolds Coated with Hydroxyapatite-PCL Composites,” Biomaterials, Vol. 31, No. 21, 2010, pp. 5498-5509. doi:10.1016/j.biomaterials.2010.03.058

[13] M. Motskin, D. M. Wright, K. Muller, N. Kyle, T. G. Gard, A. E. Porter and J. N. Skepper, "Hydroxyapatite Nano and Microparticles: Correlation of Particle Properties with Cytotoxicity and Biostability,” Biomaterials, Vol. 30, No. 19, 2009, pp. 3307-3317. doi:10.1016/j.biomaterials.2009.02.044
[14] K. I. Sallam, “Antimicrobial and Antioxidant Effects of Sodium Acetate, Sodium Lactate, and Sodium Citrate in Refrigerated Sliced Salmon," Food Control, Vol. 18, No. 5, 2007, pp. 566-575. doi:10.1016/j.foodcont.2006.02.002

[15] V. Ramaswamy, N. B. Jagtap, S. Vijayanand, D. S. Bhange and P. S. Awati, "Photocatalytic Decomposition of Methylene Blue on Nanocrystalline Titania Prepared by Different Methods," Materials Research Bulletin, Vol. 43, No. 5, 2008, pp. 1145-1152. doi:10.1016/j.materresbull.2007.06.003

[16] P. Du, A. Bueno-Lopez, M. Verbaas, A. R. Almeida, M, Makkee, J. A. Moulijn and G. Mui, "The Effect of Surface OH-Population on the Photocatalytic Activity of Rare Earth-Doped $\mathrm{P}_{25}-\mathrm{TiO}_{2}$ in Methylene Blue Degradation,” Journal of Catalysis, Vol. 260, No. 1, 2008, pp. 7580. doi:10.1016/j.jcat.2008.09.005

[17] H. Onoda, Y. Fukumura and A. Takenaka, "Preparation of Porous Aluminum Phosphate with Various Acidic and Basic Compounds," Journal of Materials Science and Engineering with Advanced Technology, Vol. 1, No. 1, 2010, pp. 97-108.

[18] L. R. Gaspar, F. B. Camargo Jr., M. D. Glaneti and P. M. B. G. M. Campos, "Evaluation of Dermatological Effects of Cosmetic Formulations Containing Saccharomyces cerevisiae Extract and Vitamins," Food and Chemical Toxicology, Vol. 46, No. 11, 2008, pp. 3493-3500. doi:10.1016/j.fct.2008.08.028

[19] S. Y. Cheng, C. W. M. Yuen, C. W. Kan, K. K. L. Cheuk, J. C. O. Tang and S. Y. Li, "A Comprehensive Study of Silicone-Based Cosmetic Textile Agent," Fibers and Polymers, Vol. 10, No. 1, 2009, pp. 132-140. doi:10.1007/s12221-009-0132-7 